\title{
МЕРЫ ПРЕДУПРЕЖДЕНИЯ ПРЕСТУПЛЕНИЙ, СОВЕРШАЕМЫХ БПЛА
}

\section{MEASURES TO PREVENT CRIMES COMMITTED BPLA}

V. Giba

Summary. At present, it is possible to observe the widespread introduction of unmanned aerial vehicles in various fields and industries: energy, geophysical exploration, mapping, search and rescue operations, road traffic control, agriculture, construction, commerce, etc. In this article, the author attempts to form specific measures aimed at preventing crimes committed by means of unmanned aerial vehicles.

Keywords: unmanned aerial vehicle, UAV, quadcopter, drone, crime, warning.
B обыденном понимании беспилотный летательный аппарат (БПЛА, беспилотник) - это новейшее изобретение, активно используемое в военных, так и коммерческих, и даже потребительских целях. Гражданские БПЛА сегодня задействованы в: энергетике, геофизической разведке, картографировании, поисково-спасательных операциях, контроле ситуации на дорогах, сельском хозяйстве, строительстве, коммерции и т.д.

Вместе с тем, малоизвестным является факт, что прообраз первого беспилотника появился еще в XIX веке. Связан он с именем инженера-изобретателя Н. Теслы, который 8 ноября 1898 г. запатентовал боевой корабль, управляемый при помощи радиоволн [13]. Идея ученого сводилась к тому, что угроза, исходящая от этого корабля, несущая в себе «безошибочную и неограниченную разрушительную силу», сможет усмирить воинственный дух наций и прекратить войны [16].

При этом, в настоящее время существенно увеличиваются сферы их применения. Руководитель Центра беспилотных систем Самарского университета Д. Овакимян однозначно говорит о том, что беспилотные летательные аппараты меняют целые индустрии, видоизменяют старые профессии и создают новые. Эксперт полагает, что сегодня можно смело вести речь о наступлении новой технологической эпохи - «эпохи дронов» [14].
Гиба Владислав Владимирович

Аспирант, Российский Университет Транспорта

(МИИТ)

vlad-giba@mail.ru

Аннотация. В настоящее время можно наблюдать широкое внедрение беспилотных летательных аппаратов в различных сферах и отраслях: энергетике, геофизической разведке, картографировании, поисково-спасательных операциях, контроле ситуации на дорогах, сельском хозяйстве, строительстве, коммерции и т.д. В настоящей статье автором предпринята попытка сформировать конкретные меры, направленные на предупреждение преступлений, совершаемых посредством беспилотных летательных аппаратов.

Ключевые слова: беспилотный летательный аппарат, беспилотник, квадрокоптер, дрон, преступление, предупреждение.

Применительно к теме настоящей статьи важное мнение, характеризующее четвертую промышленную революцию с точки зрения уголовного права, высказано А.А. Арямовым и Ю.В. Грачевой. По их словам, в зависимости от технологического уровня состояния государства и общества, от глубины проникновения IT-технологий в сферы жизни, повышается их уязвимость, в том числе, со стороны представителей организованных преступных групп, террористических организаций. Практически у любой высокой технологии есть тройное применение, в: гражданских, военных и криминальных целях. Учитывая это, последствием каждой промышленной революции становится не только открытие новых возможностей для государства и общества, но и наделение преступников не существовавшим до этого арсеналом способов и инструментов совершения преступлений [5, C. 110].

Анализ научной литературы и правоприменительной практики позволяет прийти к выводу, что посредством БПЛА возможно совершение таких преступных деяний, как:

- нанесение ударов по наземным и надводным целям, самостоятельно или посредством носимых средств поражения;

- наведение цели для других средств поражения, корректировка их применения;

- убийство (покушение на убийство) особо охраняемых лиц; 
- доставка запрещенных к обороту веществ и предметов в общественные места, а также в места лишения свободы;

- доставка взрывных устройств к потенциальной цели;

- перемещение наркотических средств через государственные границы;

- срыв движения воздушных судов;

- осуществление шпионажа и тд. [4, с. 72-73; 11, c. $109 ; 15$, с. 31-34].

Не вызывает сомнения, что государство не может (и не должно) не реагировать на возникновение новых угроз.

Представляется, что для того, чтобы устранять какое-либо преступление необходимо иметь четкое представление, почему оно возникает, какие факторы этому способствуют.

И, первый фактор, на который необходимо обратить внимание - это доступность гражданских (коммерческих, потребительских) БПЛА при недостаточном уровне государственного контроля за сферой их применения.

К примеру, если обратить внимание на введенный с 27 сентября 2019 г. в Российской Федерации механизм учета БПЛА (официально применяемый термин «беспилотные гражданские воздушные суда»), то в нем можно обнаружить следующий изъян: Правила учета беспилотных гражданских воздушных судов, утвержденные Постановлением Правительства РФ от 25 мая 2019 г. № 658 [3], в целях определения беспилотных летательных аппаратов, подлежащих регистрации, используют такой показатель, как «максимальная взлетная масса». Именно она является определяющей при выборе допустимой регистрационной процедуры. При этом, указания на «максимальную взлетную массу» нет ни в одном из документов (руководстве об эксплуатации, спецификации и пр.), выдаваемых при приобретении наиболее популярных потребительских беспилотников (к примеpy, DJI Phantom 4 Pro, YUNEEC Typhoon H520 или Autel Robotics EVO).

Как правило, в технической документации приводятся данные о весе самого беспилотника, в лучшем случае - с учетом установленных аккумуляторов и пропеллеров. С одной стороны, данный подход можно объяснить тем фактом, что бо́льшая часть БПЛА потребительского назначения не предполагает подъем какого-либо груза, следовательно, для установления максимальной взлетной массы такого аппарата должна учитываться исключительно его масса. С другой стороны, нельзя сбрасывать со счетов ситуации, при которых, пользуясь данной законодательной «лазейкой», владельцы БПлА будут сознательно избегать установленную процедуру регистрации/учета. В контексте сказанного важно учитывать также то, что на рынке представлены не только БПЛА в виде готовых изделий, есть и компоненты БПЛА, допускающие возможность сборки любительских летательных аппаратов, имеющих произвольные параметры [10, с. 48]. Тем самым, риск использования неучтенных беспилотников еще более повышается.

Имеющаяся ситуация позволяет высказать мнение о том, что первоочередной мерой, направленной на предупреждение преступлений, совершаемых посредством БПЛА, является изменение действующего порядка регистрации/учета беспилотников, имеющих максимальную взлетную массу от 250 граммов до 30 килограммов.

Второй важный фактор прямо вытекает из изучения тех сфер, где наиболее распространены факты преступного применения БПЛА. Изучение материалов судебной практики свидетельствует о том, что в настоящее время чаще всего выявляются несанкционированные полеты беспилотников над режимными объектами (в первую очередь, тюрьмами) либо вблизи от них. С их помощью предпринимаются попытки доставить заключенным наркотические средства, алкоголь, телефоны, сим-карты и пр.

Со стороны ФСИН России по данному поводу все чаще высказывается серьезная озабоченность. Отмечается, что в сравнении с 2015 г. и 2016 г., когда было зафиксировано 8 и 19 случаев использования БПЛА в целях передачи запрещенных предметов, уже в 2017 г. этот показатель вырос двое - до 43 случаев [19, с. 225]. И пока эта тенденция только лишь усиливается. В интервью директора ФСИН России А.П. Калашникова, озвученного в передаче «Расследование Эдуарда Петрова. Звонок из СИЗО» от 27 ноября 2020 г., было обращено особое внимание на то, что квадрокоптеры - это большая угроза для отечественной системы исполнения наказаний.

Опасность получения осужденными телефонов, комплектующих к ним, сим-карт и т.д. проистекает из их возможного последующего использования в целях совершения телефонных мошенничеств. Подтверждение того, что около половины всех нелегальных колл-центров в настоящее время размещается именно в исправительных, воспитательных колониях, тюрьмах и СИЗО, можно обнаружить в выступлении заместителя председателя правления ПАО «Сбербанк» С.К. Кузнецова от 29 сентября 2020 г. [6].

Информация о фактах предотвращения силами ФСИН России полетов беспилотников, несущих на себе различные запрещенные предметы, публикуется в СМИ на регулярной основе, причем в отношении практически всех 
российских регионов. Так, в конце 2020 г. сотрудниками ФКУ ИК-2 УФСИН России по Тюменской области был задержан гражданин, управлявший двумя квадрокоптерами, которые были снабжены запрещенными предметами, предназначенными для осужденных, содержащихся в колонии. При последующем осмотре принудительно посаженных аппаратов были обнаружены прикрепленные к ним свертки, включающие в себя: 3 колоды игральных карт, 7 телефонных наушников, 19 сим-карт различных операторов связи, 6 мобильных телефонов, а также прозрачный полиэтиленовый пакет с наркотическим веществом массой 0,5855 гр. [7].

Вместе с тем, к реальной уголовной ответственности за совершение подобного рода деяний привлекаются лишь единицы. Вызвана такая ситуация тем, что составом конкретного уголовного преступления охватываются лишь попытки доставки на территорию мест лишения свободы и содержания под стражей наркотических средств (ст.ст. 228, 228.1 УК РФ [2]). Что касается телефонов, сим-карт и др. запрещенных предметов, то их доставление («переброска») связывается только с угрозой наступления административной ответственности по ст. 19.12 КоАП РФ [1]. Однако, и ее применение не приводит к должному предупреждающему эффекту, т.к. в санкции указанной статьи предусматриваются невысокие суммы штрафа (от 3000 до 5000 руб.) и конфискация передаваемых предметов. [8, с. 106].
Нельзя не отметить, что разговоры о введении В УК РФ [2] нового состава преступления - «Передача средств связи в тюрьмы, колонии и следственные изоляторы» - ведутся как в научных кругах [9, с. 103-106; 21, с. 70-71], так и среди депутатов Государственной Думы РФ [17]. В частности, А.Е. Хинштейном в 2019 г. была доведена до сведения общественности информация о том, что соответствующий законопроект уже подготовлен. К сожалению, пока на официальных информационных ресурсах сведений о его передаче на рассмотрение и утверждение Государственной Думой РФ нет.

Можно предположить, что практическая реализация озвученной инициативы в настоящий момент крайне необходима, она может стать не только важной мерой предупреждения преступлений, связанных с использованием БПЛА, но и существенной преградой для совершения осужденными и подследственными новых преступлений.

Все названные выше меры в совокупности видится необходимым включить в состав специальной федеральной программы. Ее разработка и последующее принятие - это чрезвычайно актуальный вопрос, связанный с организацией в нашей стране комплексного механизма эффективного, а, что самое главное, оперативного противодействия преступлениям, совершаемым с помощью БПЛА, в частности, и киберпреступлениям, в целом.

\section{ЛИТЕРАТУРА}

1. Кодекс Российской Федерации об административных правонарушениях от 30.12.2001 № 195-Ф3 (ред. от 24.03.2021) // Собрание законодательства РФ. 2002. № 1 (ч. 1). Ст. 1; 2021. № 13 (ч. 1). Ст. 2141.

2. Уголовный кодекс Российской Федерации от 13.06.1996 № 63-Ф3 (ред. от 24.02.2021) // Собрание законодательства РФ. 1996. № 25. Ст. 2954; 2021. № 9. Ст. 1472.

3. Постановление Правительства РФ от 25.05 .2019 № 658 «06 утверждении Правил учета беспилотных гражданских воздушных судов с максимальной взлетной массой от 0,25 килограмма до 30 килограммов, ввезенных в Российскую Федерацию или произведенных в Российской Федерации» // Собрание законодательства РФ. 2019. № 22. С. 2824.

4. Аниськов Р.В., Архипова Е.В., Гордеев А.А., Пугачев А.Н. К вопросу борьбы с незаконным использованием беспилотных летательных аппаратов коммерческого типа // Вопросы оборонной техники. Серия 16: Технические средства противодействия терроризму. 2017. № 9-10. С. $72-73$.

5. Арямов А.А., Грачева Ю.В. Цифровизация: уголовно-правовые риски в сфере экономики // Актуальные проблемы российского права. 2019 . № 6. С. 110.

6. В Сбербанке заявили, что почти половина всех мошеннических колл-центров находится в тюрьмах // ТАСС. 29.09.2020. [Эл. ресурс]. Режим доступа: https://tass.ru/ekonomika/9576557 (дата обращения: 13.04.2021).

7. В тюменской колонии поймали квадрокоптер с посылкой для заключенных // Тюменская область сегодня. 10.11.2020. [Эл. ресурс]. Режим доступа: httрs:// tumentoday.ru/2020/11/10/v-tyumenskoj-kolonii-pojmali-kvadrokopter-s-posylkoj-dlya-zaklyuchennyh/ (дата обращения: 13.04.2021).

8. Горовой В.В. Борьба с использованием сотовых телефонов лицами, содержащимися в следственных изоляторах уголовно-исполнительной системы России // Уголовно-исполнительная система: педагогика, психология и право: Материалы Всероссийской научно-практической конференции (г. Томск, 19-20 апреля 2018 г.) / Под общ. ред. В.А. Уткина. Томск: Изд-во ФКУ ДПО «Томский институт повышения квалификации работников Федеральной службы исполнения наказаний», 2018. С. 106.

9. Горовой В.В. Криминализация использования средств мобильной связи лицами, содержащимися под стражей // Труды Академии управления МВД России. 2018. № 2. С. 103-106.

10. Демуренко К.А. Дроны — новая угроза с высоты // Алгоритм безопасности. 2016. № 2. С. 48.

11. Демьянович М.А. Использование беспилотных летательных аппаратов в преступных целях: методы противодействия и борьбы // Правопорядок: история, теория, практика. 2019. № 2. С. 109. 
12. Клейменова Л. Индустрия 4.0 в 40 цифрах и фактах // Информационное агентство «РБК». 27.08.2020. [Эл. ресурс]. Режим доступа: https://trends.rbc.ru/ trends/industry/5daef6429a7947c1bfe43006 (дата обращения: 13.04.2021).

13. Костюченко Ю. Беспилотники, опередившие свою эпоху: уникальное изобретение Николы Теслы // Информационно-развлекательный портал «Аvia.pro». 27.10.2016. [Эл. ресурс]. Режим доступа: https://avia.pro/blog/bespilotniki-operedivshie-svoyu-epohu-unikalnoe-izobretenie-nikoly-tesly (дата обращения: 13.04.2021).

14. Мир после вируса — мир дронов? Эксперт раскрыл черты новой реальности [Интервью Руководителем Центра беспилотных систем Самарского университета Д. Овакимяном] // РИА Новости. 07.05.2020. [Эл. ресурс]. Режим доступа: https://ria.ru/20200507/1571024843.html (дата 0бращения: 13.04.2021).

15. Митрофанов Д.Г., Шишков С.В. Инновационный подход к вопросу обнаружения малогабаритных беспилотных летательных аппаратов // Известия ЮФу. Технические науки. 2018. № 1. С. 31-34.

16. Передельский Д. Найден патент на самое страшное изобретение Николы Теслы // Российская газета. 22.08.2016. [Эл. ресурс]. Режим доступа: httрs:// rg.ru/2016/08/22/najden-patent-na-samoe-strashnoe-izobretenie-nikoly-tesly.html (дата обращения: 13.04.2021).

17. Петров И. Преступный гаджет: за передачу мобильных телефонов за решетку введут новую статью УК // Российская газета. 16.12.2019. [Эл. ресурс]. Режим доступа: https://rg.ru/2019/12/16/za-peredachu-mobilnikov-za-reshetku-vvedut-ugolovnuiu-otvetstvennost.html (дата обращения: 13.04.2021).

18. Румянцев Н.В., Колотушкин С.М. Современные методы и средства противодействия использованию беспилотных летательных аппаратов, для доставки запрещенных предметов в учреждения уголовно-исполнительной системы России // Вестник Московского университета МВД России. 2018 № 4. С. 225.

19. Смирнов С.Н., Миннахметов Р.И., Моисеев Н.Д. 06 ответственности граждан за доставку либо попытку доставки запрещенных предметов лицам, содержащимся в учреждениях уголовно-исполнительной системы Российской Федерации или изоляторах временного содержания // Ведомости уголовно-исполнительной системы. 2019. № 9. С. 46.

20. Сулейманов Т.А. 06 установлении уголовной ответственности за передачу запрещенных предметов лицам, содержащимся в учреждениях уголовно-исполнительной системы, следственных изоляторах или изоляторах временного содержания // Человек: преступление и наказание. 2012. № 3. С. 70-71.

21. Федоров А.А. Дрон, как потенциальное орудие убийства // Актуальные проблемы уголовного судопроизводства и криминалистики: Материалы Интернет-конференции Сибирского юридического университета, 2020. [Эл. ресурс]. Режим доступа: https://conf.siblu.ru/dron-kak-potencialnoe-orudie-ubiystva (дата обращения: 13.04.2021).

22. Шваб К. Четвертая промышленная революция. М.: Эксмо, 2016. С. 17.

(с) Гиба Владислав Владимирович ( vlad-giba@mail.ru ).

Журнал «Современная наука: актуальные проблемы теории и практики»

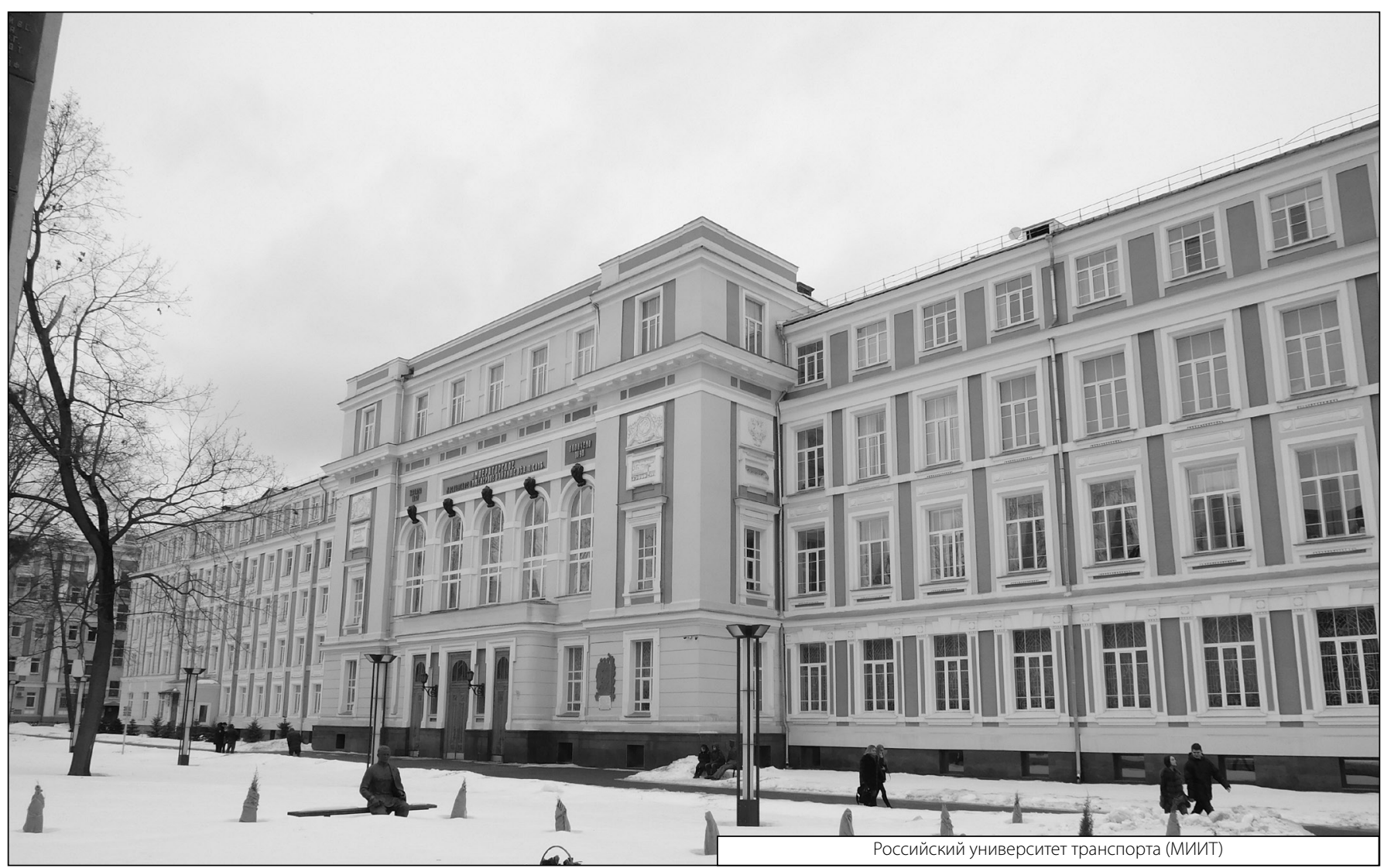

